Matematikai Közlemények

V. kötet, 2017

doi:10.20312/dim.2017.01

\title{
Hardy inequality for star-shaped domains
}

\author{
Sándor Zsuppán \\ Berzsenyi Dániel Evangélikus (Líceum) Gimnázium és Kollégium \\ zsuppans@gmail.com
}

\begin{abstract}
ÖSSZEFOGLALÓ. Csillagszerü tartomány Hardy egyenlőtlenségben szereplő konstansának egy felső becslését adjuk a tartomány peremétôl vett távolságfüggvény segítségével. Amennyiben a szokásos euklidészi peremtávolságfüggvény helyett a sugárirányú peremtávolságot alkalmazzuk a Hardy egyenlőtlenségben, akkor a minden csillagszerü tartomány konstansa egyenlő az egy dimenziós egyenlőtlenségben szereplő konstanssal.
\end{abstract}

ABSTRACT. We investigate in this note the Hardy inequality on a star-shaped domain. We give an upper estimation for the Hardy constant figuring in the inequality in terms of the distance to the boundary function. Besides the Euclidean boundary distance function in the inequality we also consider the distance function in the radial direction for which the Hardy constant of the star-shaped domain turns out to be equal to the constant of an interval.

\section{Introduction}

The Hardy inequality [13] states that if $1<p<\infty$ and $\alpha<p-1$ then

$$
\int_{0}^{\infty} \frac{|u(x)|^{p}}{x^{p-\alpha}} \mathrm{d} x \leq\left(\frac{p}{p-\alpha-1}\right)^{p} \int_{0}^{\infty}\left|u^{\prime}(x)\right|^{p} x^{\alpha} \mathrm{d} x
$$

for any function $u$ absolutely continuous on $[0 ; \infty[$. provided $u(0)=0$. If $u \neq 0$ then the inequality in (1) is strict but the constant $\left(\frac{p}{p-\alpha-1}\right)^{p}$ is sharp.

It was generalized in [17] for Lipschitz domains $\Omega \subset \mathbb{R}^{n}, n \geq 2$, i.e. there is a constant $H$ depending on the domain $\Omega$ and on the values of $n, p$ and $\alpha$ such that

$$
\int_{\Omega} \frac{|u(x)|^{p}}{d(x)^{p-\alpha}} \mathrm{d} x \leq H \int_{\Omega}|u(x)|^{p} d(x)^{\alpha} \mathrm{d} x
$$

for every $u \in C_{0}^{\infty}(\Omega)$, where $d(x)=\operatorname{dist}(x, \partial \Omega)$ denotes the distance to the boundary function. The least possible value of $H$ in (2) is called the Hardy constant of $\Omega$ and it is denoted by $H_{\Omega}(n, p, \alpha)$ or simply by $H_{\Omega}$ by suppressing the other parameters in the notation. Conditions for the finiteness of $H_{\Omega}$ or extensions of (2) by some terms on the left-hand side or for other weight functions than the boundary distance $d$ were investigated by many authors,

KULCSSZAVAK. Hardy egyenlőtlenség, Hardy konstans, csillagszerü tartomány, peremtávolság függvény.

KEYWORDS. Hardy inequality, Hardy constant, star-shaped domain, boundary distance function. 
see [1-12,14-19] and references given therein. For example one has $H_{\Omega}(n, p, 0)=\left(\frac{p}{p-1}\right)^{p}$ for convex domains in $\mathbb{R}^{n}$, especially $H_{\Omega}(n, 2,0)=4$ but there are other nonconvex domains with $H_{\Omega}(n, 2,0)=4$, see e.g. $[4,6,9]$.

According to Ancona [1] we have $H_{\Omega}(n, 2,0) \leq 16$ for simply connected planar domains, moreover, for arbitrary planar domains Avkhadiev [3] proved

$$
\min \{2 ; p\} M_{0}(\Omega) \leq H_{\Omega}(2 ; p ; p-2)^{\frac{1}{p}} \leq 2 p\left(\pi M_{0}(\Omega)+\frac{\Gamma\left(\frac{1}{4}\right)^{4}}{4 \pi^{2}}\right)^{2}
$$

where $M_{0}(\Omega)$ denotes the maximal module of annuli centred on the boundary contained in $\Omega$ and separating its boundary, especially $M_{0}(\Omega)=0$ for simply connected domains. Hence $H_{\Omega}(2 ; p ; p-2)$ is finite iff the boundary of the domain is uniformly perfect. However, it is still an open question to determine the exact value of $H_{\Omega}$ in (2) for nonconvex domains in $\mathbb{R}^{n}$.

In this note the Hardy constant $H_{\Omega}$ in (2) of a star-shaped domain is estimated by elementary means.

\section{Hardy constant of a star-shaped domain}

Let $\Omega \subset \mathbb{R}^{n}, n \geq 2$ be a star-shaped domain with respect to the origin the boundary of which is parametrized by the function $f(\theta)=f\left(\theta_{1}, \ldots, \theta_{n-1}\right)$, i.e.

$$
\Omega=\{(r, \theta): r<f(\theta), \theta \in \mathbb{S}\}
$$

where $\mathbb{S}$ denotes the domain of the angles of the $n$-dimensional spherical coordinate system, that is $0 \leq \theta_{j} \leq \pi$ for $j=1, \ldots, n-2$ and $0 \leq \theta_{n-1} \leq 2 \pi$. According to Ch. 1.1.8 in [16] in this case $f$ is a Lipschitz function on $\mathbb{S}$.

For any $u \in C_{0}^{\infty}(\Omega)$ we have $u(f(\theta), \theta)=0$ and therefore

$$
-u(r, \theta)^{p}=\int_{r}^{f(\theta)} p u(\rho, \theta)^{p-1} \partial_{\rho} u(\rho, \theta) \mathrm{d} \rho .
$$

We take the absolute value and estimate the integral

$$
|u(r, \theta)|^{p} \leq \int_{r}^{f(\theta)} p|u(\rho, \theta)|^{p-1}\left|\partial_{\rho} u(\rho, \theta)\right| \mathrm{d} \rho .
$$

Let $\psi=\psi(r, \theta)$ denote a locally integrable nonnegative weight function on $\Omega$. We multiply (6) by $\psi$ and integrate on $\Omega$. On the left-hand side of (6) we obtain

$$
\int_{\Omega}|u|^{p} \psi=\int_{\mathbb{S}} \int_{0}^{f(\theta)}|u(r, \theta)|^{p} \psi(r, \theta) r^{n-1} J(\theta) \mathrm{d} r \mathrm{~d} \theta
$$

where $J(\theta)=\prod_{j=1}^{n-2} \sin ^{n-1-j} \theta_{j}$ is the part of the Jacobian containing the angles. On the righthand side of (6) we change the integrations with respect to the variables $\rho$ and $r$ :

$$
\int_{\mathbb{S}} \int_{0}^{f(\theta)}\left[\frac{1}{\rho^{n-1}} \int_{0}^{\rho} r^{n-1} \psi(r, \theta) \mathrm{d} r\right] p|u(\rho, \theta)|^{p-1}\left|\partial_{\rho} u(\rho, \theta)\right| \rho^{n-1} J(\theta) \mathrm{d} \rho \mathrm{d} \theta .
$$

Using also $\left|\partial_{\rho} u(\rho, \theta)\right| \leq|\nabla u(\rho, \theta)|$ we obtain the following inequality 


$$
\int_{\Omega}|u|^{p} \psi \leq \int_{\Omega} p|u|^{p-1}|\nabla u| \Psi
$$

where

$$
\Psi(\rho, \theta)=\frac{1}{\rho^{n-1}} \int_{0}^{\rho} r^{n-1} \psi(r, \theta) \mathrm{d} r
$$

This definition of the function $\Psi$ by (10) makes also sense when $\rho \rightarrow 0$ because

$$
\Psi(\rho, \theta) \leq \int_{0}^{\rho} \psi(r, \theta) \mathrm{d} r
$$

and hence $\lim _{\rho \rightarrow 0} \Psi(\rho, \theta)=0$. Expand the right-hand side of (9) by the factor $\psi^{\frac{1}{q}}$ and estimate by Hölder's inequality:

$$
\begin{aligned}
\int_{\Omega} p|u|^{p-1} \psi^{\frac{1}{q}}|\nabla u| \psi^{-\frac{1}{q}} \Psi & \leq p\left(\int_{\Omega}|u|^{(p-1) q} \psi\right)^{\frac{1}{q}}\left(\int_{\Omega}|\nabla u|^{p} \psi^{-\frac{p}{q}} \Psi^{p}\right)^{\frac{1}{p}} \\
& =p\left(\int_{\Omega}|u|^{p} \psi\right)^{\frac{1}{q}}\left(\int_{\Omega}|\nabla u|^{p} \psi^{1-p} \Psi^{p}\right)^{\frac{1}{p}}
\end{aligned}
$$

where we have also used $(p-1) q=p$ as a consequence of $\frac{1}{p}+\frac{1}{q}=1$. Substituting this into (9) implies

$$
\int_{\Omega}|u|^{p} \psi \leq p\left(\int_{\Omega}|u|^{p} \psi\right)^{\frac{1}{q}}\left(\int_{\Omega}|\nabla u|^{p} \psi^{1-p} \Psi^{p}\right)^{\frac{1}{p}}
$$

Dividing both sides by $\left(\int_{\Omega}|u|^{p} \psi\right)^{\frac{1}{q}}$ and using again $\frac{1}{p}+\frac{1}{q}=1$ implies

$$
\int_{\Omega}|u|^{p} \psi \leq p^{p} \int_{\Omega}|\nabla u|^{p} \psi^{1-p} \Psi^{p}
$$

In order to obtain (2) we substitute the weight function

$$
\psi=\frac{1}{d^{p-\alpha}}
$$

compute $\Psi$ and estimate the right-hand side of (13). There follows

$$
\int_{\Omega} \frac{|u|^{p}}{d^{p-\alpha}} \leq p^{p} \max _{(\rho, \theta) \in \Omega}\left(\frac{d(\rho, \theta)^{p-\alpha-1}}{\rho^{n-1}} \int_{0}^{\rho} \frac{r^{n-1}}{d(r, \theta)^{p-\alpha}} \mathrm{d} r\right)^{p} \int_{\Omega}|\nabla u|^{p} d^{\alpha},
$$

which gives the upper estimation for the Hardy constant of the star-shaped domain $\Omega$ in case $1<p<\infty$ and $\alpha<p-1$ :

$$
H_{\Omega} \leq p^{p} \max _{(\rho, \theta) \in \Omega}\left(\frac{d(\rho, \theta)^{p-\alpha-1}}{\rho^{n-1}} \int_{0}^{\rho} \frac{r^{n-1}}{d(r, \theta)^{p-\alpha}} \mathrm{d} r\right)^{p} .
$$

The maximum in (16) is finite since

$$
\frac{d(\rho, \theta)^{p-\alpha-1}}{\rho^{n-1}} \int_{0}^{\rho} \frac{r^{n-1}}{d(r, \theta)^{p-\alpha}} \mathrm{d} r \leq d(\rho, \theta)^{p-\alpha-1} \int_{0}^{\rho} \frac{1}{d(r, \theta)^{p-\alpha}} \mathrm{d} r
$$


and by the L'Hospital rule we have

$$
\lim _{\rho \rightarrow f(\theta)} d(\rho, \theta)^{p-\alpha-1} \int_{0}^{\rho} \frac{1}{d(r, \theta)^{p-\alpha}} \mathrm{d} r=\frac{-1}{(p-\alpha-1) \partial_{\rho} d(f(\theta), \theta)} .
$$

and $\partial_{\rho} d(f(\theta), \theta)=-\cos \angle(x, n)$ for almost every $\theta \in \mathbb{S}$, where $\angle(x, n)$ denotes the angle between the position vector $x=(f(\theta), \theta)$ and the outer unit normal vector to the boundary of $\Omega$ at $x$.

Theorem 2.1 If $\Omega$ is a star-shaped domain in $\mathbb{R}^{n}, n \geq 2$ with respect to the origin, then we have (16) for the Hardy constant in (2).

Remark 2.2 The upper estimation (16) for the Hardy constant is computable only if one knows the distance to the boundary function $d$ of the domain. In order to obtain a more geometrical version we denote by $F(\rho, \theta)$ the right hand side of (17) and compute its partial derivative with respect to the variable $\rho$

$$
\partial_{\rho} F(\rho, \theta)=\frac{1}{d(\rho, \theta)}+(p-\alpha-1) \frac{\partial_{\rho} d(\rho, \theta)}{d(\rho, \theta)} F(\rho, \theta)
$$

Hence if $\partial_{\rho} F(\rho, \theta)=0$ then $F(\rho, \theta)=\frac{-1}{(p-\alpha-1) \partial_{\rho} d(\rho, \theta)}$ and there follows

$$
\max _{\rho \in[0 ; f(\theta)]} F(\rho, \theta) \leq \max _{\rho \in[0 ; f(\theta)]} \frac{1}{(p-\alpha-1)\left|\partial_{\rho} d(\rho, \theta)\right|}
$$

which implies

$$
H_{\Omega} \leq\left(\frac{p}{p-\alpha-1}\right)^{p}\left(\max _{\theta \in \mathbb{S}} \max _{\rho \in[0 ; f(\theta)]} \frac{1}{\partial_{\rho} d(\rho, \theta) \mid}\right)^{p}
$$

Here $\left|\partial_{\rho} d(\rho, \theta)\right|$ is the cosine of the angle between the position vector $x=(\rho, \theta)$ and the outer normal vector on the boundary at $x$ of that subdomain which is enclosed by a level curve $d=$ constant.

Example 2.3 Let $\Omega=B_{R}(0)$ be an $n$-dimensional ball with radius $R$ centered in the origin. We can directly compute the upper estimation (15) by substituting $d(\rho, \theta)=R-\rho$ or we can use (21) and we obtain

$$
H_{B_{R}(0)} \leq\left(\frac{p}{p-\alpha-1}\right)^{p}
$$

for $1<p<\infty$ and $\alpha<p-1$ just as in the case of an intervall.

Remark 2.4 If $\Omega$ is a convex domain then using $\left|\partial_{\rho} d(x)\right| \leq 1$ for $x \in \Omega$ the upper estimator in (21) is at least $\left(\frac{p}{p-\alpha-1}\right)^{p}$ which is known to be the sharp upper estimator of the Hardy constant for convex domains.

Remark 2.5 Instead of the weight (14) we can substitute another weight

$$
\psi(\rho, \theta)=\frac{1}{(f(\theta)-\rho)^{p-\alpha}} .
$$


In [11] a partially similar weight was considered with an additional singularity at the origin. Using (23) direct computation gives

$$
\Psi(\rho, \theta) \leq \frac{1}{p-\alpha-1}\left(\frac{1}{(f(\theta)-\rho)^{p-\alpha-1}}-\frac{1}{f(\theta)^{p-\alpha-1}}\right) .
$$

This can be substituted into the inequality (13):

$$
\int_{\Omega} \frac{|u|^{p}}{(f(\theta)-\rho)^{p-\alpha}} \leq\left(\frac{p}{p-\alpha-1}\right)^{p} \int_{\Omega}|\nabla u|^{p}(f(\theta)-\rho)^{\alpha} .
$$

Hence if we use the weight (23) instead of (14) then every star-shaped domain behaves like an interval concerning the Hardy inequality, c.f. (1) and (25). Moreover, if the radial distance $f(\theta)-\rho$ of the point $(\rho, \theta) \in \Omega$ is comparable to its ordinary distance $d(\rho, \theta)$ to the boundary, that is

$$
\varepsilon(f(\theta)-\rho) \leq d(\rho, \theta) \leq f(\theta)-\rho
$$

for some fixed $0<\varepsilon \leq 1$ then there follows by (25)

$$
\int_{\Omega} \frac{|u|^{p}}{d^{p-\alpha}} \leq\left(\frac{p}{p-\alpha-1}\right)^{p} \frac{1}{\varepsilon^{p}} \int_{\Omega}|\nabla u|^{p} d^{\alpha},
$$

which gives

$$
H_{\Omega} \leq\left(\frac{p}{p-\alpha-1}\right)^{p}\left(\max _{\theta \in \mathbb{S}} \max _{\rho \in[0 ; f(\theta)]} \frac{f(\theta)-\rho}{d(\rho, \theta)}\right)^{p}
$$

for the Hardy constant.

Remark 2.6 The estimations (16), (21) and (28) depend not only on the domain and on the parameters $p$ and $\alpha$ but also on the choice of the center of polar coordinates. For example if one chooses the centre of polar coordinates in a distance of $0 \leq \delta<1$ from the centre of the unit ball and calculates the parametrization of the unit ball then one has $\varepsilon=\frac{1}{\sqrt{1+\delta^{2}}}$ in (26) and the estimation (28) gives

$$
H_{\Omega} \leq\left(\frac{p}{p-\alpha-1}\right)^{p}{\sqrt{1+\delta^{2}}}^{p}
$$

which is bigger than the exact value in (22) if $0<\delta<1$.

Conclusion The upper estimations for the Hardy constant of a star-shaped domain considered in this note are novel to the authors best knowledge, however, they are difficult to calculate explicitly in terms of simple shape characteristics of the domain. In the case of the unit ball the estimate gives the value of the known sharp constant. If one chooses the distance to the boundary in the radial direction instead of the ordinary distance in the Hardy inequality then the Hardy constant of any star-shaped domain is the same as that of an interval. 


\section{References}

[1] Ancona A., On strong barriers and an inequality of Hardy for domains in $\mathbb{R}^{n}$, J. London Math. Soc. (2) 37 (1986), 274-290, doi:10.1112/jlms/s2-34.2.274.

[2] Babuška I., Aziz A. K., Survey lectures on the mathematical foundations of the finite element method, in The mathematical foundations of the finite element method with applications to partial differential equations (Proc. Sympos., Univ. Maryland, Baltimore, Md., 1972), Academic Press, New York, 1972, pp. 1-359, doi:10.1016/B978-0-12-068650-6.50007-1.

[3] Avkhadiev F.G., Hardy type inequalities in higher dimensions with explicit estimate of constants, Lobachevskii J. Math. 21 (2006), 3-31.

[4] Avkhadiev F. G., A geometric description of domains whose Hardy constant is equal to 1/4, Izvestiya: Mathematics 78(5) (2014), 855-876.

[5] Avkhadiev F., Laptev A., Hardy inequalities for nonconvex domains, International Mathematical Series. Around Research of Vladimir Maz'ya, I, vol. 11, Springer, New York (2010), 1-12, doi:10.1007/978-14419-1341-8_1.

[6] Barbatis G., Filippas S., Tertikas A., A unified approach to improved $L_{p}$ Hardy inequalities with best constants, Trans. Amer. Math. Soc. 356(6) (2004), 2169-2196 (electronic).

[7] Boas H. B., Straube E. J., Integral inequalities of Hardy and Poincare type, Proc. Amer. Math. Soc. 103 (1988), 172-176, doi:10.2307/2047547.

[8] Davies E. B., Some norm bounds and quadratic form inequalities for Schrödinger operators, II. J. Operator Theory 12 (1984) 177-196.

[9] Davies E.B., The Hardy constant, Quart. J. Math. Oxford (2), 46 (1995), 417-431, doi:10.1093/qmath/46.4.417.

[10] Davies E. B., A review of Hardy inequalities, in: The Maz'ya Anniversary Collection, vol. 2, Oper. Theory Adv. Appl., vol 110 (Birkhäuser, Basel, 1999), 55-67, doi:10.1007/978-3-0348-8672-7_5.

[11] Fabricant A., Kutev N., Rangelov T., Sharp Hardy Inequalities in Star-shaped Domains with Double Singular Kernels, Mediterr. J. Math. (2017) 14: 21, doi:10.1007/s00009-016-0831-4.

[12] Franck R.L., Loss M., Hardy-Sobolev-Maz'ya inequalities for arbitrary domains, J. Math. Pures Appl. 97 (2012), 39-54, doi:10.1016/j.matpur.2011.04.004.

[13] Hardy G. H., An inequality between integrals. Messenger Math. 54 (1925), 150-156.

[14] Kufner A., Weighted Sobolev Spaces, Wiley, New York (1985).

[15] Laptev A., Sobolev A. V., Hardy inequalities for simply connected planar domains, Am. Math. Soc. Transl., Ser. 2, Adv. Math. Sci., 225, (2008), 133-140, doi:10.1090/trans2/225.

[16] Maz'ya V.G., Sobolev spaces, Springer Series in Soviet Mathematics, Springer-Verlag, Berlin, 1985. Translated from the Russian by T.O. Shaposhnikova, doi:10.1007/978-3-642-15564-2.

[17] Nečas J., Sur une méthode pour résoudre les équations aux dérivées partielles du type elliptique, voisine de la variationnelle, Ann. Scuola Norm. Sup. Pisa (3) 16 (1962), 305-326.

[18] Tidblom J., A Geometrical Version of Hardy's Inequality for $W_{0}^{1, p}(\Omega)$, Proc. Amer. Math. Soc. 132(8) (2004), 2265-2271, doi:10.1090/S0002-9939-04-07526-4.

[19] Wannebo A. , Hardy inequalities, Proc. Amer. Math. Soc. 109 (1990), 85-95, doi:10.2307/2048366. 